\title{
Ventilator-associated Pneumonia
}

\section{Pravin Charles ${ }^{1}$, Arunava Kali ${ }^{1}$, Joshy M Easow ${ }^{1}$, Noyal Maria Joseph ${ }^{1}$, Murugesan Ravishankar ${ }^{2}$,} Srirangaraj Srinivasan ${ }^{1}$, Shailesh Kumar ${ }^{1}$, Sivaraman Umadevi1

1. Department of Microbiology, Mahatma Gandhi Medical College and Research Institute, Pondicherry, India

2. Department of Anaesthesiology, Mahatma Gandhi Medical College and Research Institute, Pondicherry, India

\section{REVIEW}

Please cite this paper as: Charles MVP, Kali A, Easow JM, Joseph NM, Ravishankar M, Srinivasan S, Kumar S, Umadevi S. Ventilator-associated pneumonia.
AMJ
2014,
7, 8,
334-344.

http://doi.org/10.21767/AMJ.2014.2105

\section{Corresponding Author:}

MV Pravin Charles

Department of Microbiology

Mahatma Gandhi Medical College and Research Institute

Pillaiyarkuppam, Pondicherry-607402, India

Email: dr_mvpravincharles@yahoo.com

\section{ABSTRACT}

\section{Background}

Ventilator-associated pneumonia (VAP) is a type of nosocomial pneumonia that occurs in patients who receive mechanical ventilation (MV). According to the International Nosocomial Infection Control Consortium (INICC), the overall rate of VAP is 13.6 per 1,000 ventilator days. The incidence varies according to the patient group and hospital setting. The incidence of VAP ranges from 13-51 per 1,000 ventilation days. Early diagnosis of VAP with appropriate antibiotic therapy can reduce the emergence of resistant organisms.

\section{Method}

The aim of this review was to provide an overview of the incidence, risk factors, aetiology, pathogenesis, treatment, and prevention of VAP. A literature search for VAP was done through the PUBMED/MEDLINE database. This review outlines VAP's risk factors, diagnostic methods, associated organisms, and treatment modalities.

\section{Conclusion}

VAP is a common nosocomial infection associated with ventilated patients. The mortality associated with VAP is high. The organisms associated with VAP and their resistance pattern varies depending on the patient group and hospital setting. The diagnostic methods available for VAP are not universal; however, a proper infection control policy with appropriate antibiotic usage can reduce the mortality rate among ventilated patients.

\section{Key Words}

Ventilator-associated pneumonia, mechanical ventilation, clinical pulmonary infection score

\section{What this review adds:}

\section{What is known about this topic?}

VAP is a type of nosocomial pneumonia, which increases mortality rates among critically ill patients.

\section{What new information is offered in this review?}

This review gives an overview of the incidence, pathogenesis, risk factors, aetiology, treatment, and prevention of VAP.

3. What are the implications for research, policy, or practice?

Greater awareness of VAP's risk factors, incidence, pathogenesis, and treatment can facilitate the creation of appropriate infection control measures to curb VAP among critically ill patients.

\section{Background}

Ventilator-associated pneumonia (VAP) is a type of nosocomial pneumonia that occurs in patients who receive mechanical ventilation. ${ }^{1}$ VAP is usually acquired in the hospital setting approximately 48-72 hours after mechanical ventilation. The main aim of mechanical ventilation is to aid in gas exchange without causing trauma to the lungs. Unfortunately, MV can harm the lungs by the stress and strain developed in the lung. High pressure and volume can cause barotrauma and volutrauma to the lungs, which is followed by biotrauma and atelectrauma. According to the International Nosocomial Infection Control Consortium (INICC), the overall rate of VAP is 13.6 per 1,000 ventilator days. ${ }^{2}$ The incidence varies according to the patient group and hospital setting. The incidence of VAP ranges from 13-51 per 1,000 ventilation days. ${ }^{3}$ The mean duration of 
occurrence of VAP is around 5-7 days. The mortality associated with VAP ranges from 24-76 per cent, and is even higher among critically ill patients. ${ }^{4}$

VAP increases the patient stay in the ICU and indirectly increases the cost of patient management. Based on the time of onset of VAP, it can be divided into two types. Early-onset VAP occurs during the first four days of mechanical ventilation and is usually caused by antibiotic sensitive bacteria. Lateonset VAP develops five or more days after initiation of MV and is caused by multidrug-resistant (MDR) pathogens. ${ }^{5}$ Early diagnosis of VAP with appropriate antibiotic therapy can reduce the emergence of resistant organisms.

\section{Pathogenesis}

VAP occurs in patients who are ventilated either by an endotracheal tube or tracheostomy. Pneumonia is a host response to bacterial invasion. The normal physiology of the respiratory system is to clear the secretions from the larynx and pharynx either by mucociliary action or cough reflex. Mechanically ventilated patients are unconscious and there is no clearance of the secretions in the oropharynx. The defence mechanisms are also ineffective in patients with reduced immune response. ${ }^{6}$ The normal oral colonisers start increasing in number. These colonisers along with the secretions collected pass along the tracheal tube. It can form a biofilm and reach the distal airways leading to pneumonia. ${ }^{7}$ The organism reaching the distal airway then overcomes the host immune response. In addition, cofactors like pulmonary edema and previous lung infections favour the bacterial multiplication. The source of infection in most patients with VAP is either the oral flora or bacteraemia. The other sources can be the stomach contents, ventilator circuits, humidifiers, and nebulisers. ${ }^{8}$

\section{Risk factors}

Many factors contribute to the development of VAP. The factors associated with the host response to the ventilation are called host factors. The other group, intervention factors, occur due to intervention.

\section{Host factors}

\section{Trauma}

VAP cases include injured patients, who are at greater risk for VAP than medically ill patients. Rello et al. reported that the overall mortality rate was 19.8 per cent in this group. ${ }^{9}$ Similarly, Singh et al. reported that early VAP due to $H$. influenzae was significantly more common in trauma patients, compared with other surgical and postoperative patients. The reason was most of the healthy patients were $H$. influenzae carriers, and in patients with chronic illness, these organisms were replaced by resistant organisms. ${ }^{10}$ The microbes isolated from early- and late-onset VAP appear to be the same among injured patients and medically ill patients. ${ }^{11}$

\section{Post-surgical and burns patients}

Around one-third of post-surgical patients have associated pulmonary infiltrate. In a study conducted by Garibaldi et al., it was found that 17 per cent of postoperative patients had pneumonia. ${ }^{12}$ Longer duration of surgery and history of smoking are associated with an increase in development of VAP. Patients with serious burn injuries are at high risk for developing VAP. These patients are more prone if there is an inhalational injury or if the patient is intoxicated at the time of admission. ${ }^{13}$ The markers associated with VAP in these patients include low serum albumin concentration and a high score on the American Society of Anesthesiologists Physical Status Classification System. ${ }^{12}$

\section{Acute respiratory distress syndrome (ARDS)}

VAP is a common complication in patients with acute respiratory distress syndrome (ARDS) and lung injury. It is probably due to prolonged mechanical ventilation among these patients. Chastre et al. conducted a study on ARDS and its influence on VAP: they found that VAP occurred in 55 per cent of patients with ARDS, as compared with 28 per cent of patients without ARDS, due to prolonged ventilation in these patients compared to the non-ARDS patients. ${ }^{14}$ In a study directed against diagnostic testing of ARDS patients with suspected VAP, it has been found that positive quantitative cultures confirmed VAP in 37-60 per cent of cases. ${ }^{15}$ Staphylococci and gram-negative bacilli were the most common bacterial isolates. Methicillinresistant Staphylococcus aureus (MRSA) was significantly more common in patients with ARDS.

\section{Chronic obstructive pulmonary disease (COPD)}

COPD is recognised as a risk factor for the development of VAP. It may be due to the patient's advanced age, high colonisation of lower airways, inhibition of mucociliary function due to cigarette smoking, the inability to generate an effective cough because of airflow obstruction, and the suppressive effects of corticosteroids on lung host defenses. When patients with COPD develop VAP, they are at increased risk for infection with $H$. influenzae, as well as Pseudomonas species, MRSA, and Aspergillus species. ${ }^{16}$

\section{Upper respiratory tract colonisation}

The oral cavity contains normal flora, which under certain circumstances can colonise in the upper respiratory tract. The endotracheal tube in place causes local trauma and 
inflammation. It leads to colonisation of the upper respiratory tract and aspiration of the pathogens around the cuff. ${ }^{5} \mathrm{~A}$ high volume, low pressure cuff reduces the rate to 20 percent compared to a 56 per cent reduction with a low volume, high pressure cuff. The oropharyngeal secretions can be prevented from aspiration by continuous or intermittent suctioning.

\section{Enteral feeding}

Ventilated patients are given enteral feeding by a nasogastric tube. Enteral feeding increases the gastric secretions and $\mathrm{pH}$, which leads to gram-negative bacilli colonising the stomach. This subsequently leads to aspiration of the stomach contents and hence pneumonia. To circumvent this condition trials were conducted comparing intermittent enteral feeding (IEF) and continuous enteral feeding (CEF). A randomised control study was conducted on 60 patients with CEF and IEF. It showed that though the IEF group showed a reduction in the gastric $\mathrm{pH}$, around 80 per cent of patients were colonised in both groups. ${ }^{17}$ Another method of feeding critically ill patients is parenteral nutrition, but most clinicians prefer enteral nutrition to parenteral nutrition. Because parenteral nutrition is associated with infection of the access line, it is costly and also not as effective nutritionally as enteral formulations.

\section{Sinusitis}

Sinusitis is mostly associated with nasotracheal intubation. There are many studies comparing the risk of nosocomial sinusitis and the associated risk of VAP. VAP was more common in patients with infectious sinusitis, with 67 per cent of them developing lung infection following the diagnosis of sinusitis. $^{18}$

\section{Biofilm}

Biofilm is a complex polysaccharide matrix that forms a slimy coating on the surface and within lumen of the endotracheal tube. Biofilm plays an important role in pathogenesis supporting colonisation of the endotracheal tube and facilitating repeated inoculation of the lower airway. ${ }^{7}$ Organisms are resistant to drugs when they are present within the biofilm.

\section{Intervention factors}

\section{Duration of mechanical ventilation}

VAP is defined as pneumonia occurring after 48 hours of mechanical ventilation. This definition helps to distinguish hospital-acquired VAP from community-acquired infections that were incubating at the time of intubation but were not clinically evident until one to two days later. The duration of mechanical ventilation is an important risk factor for the development of VAP. ${ }^{19}$ Rello et al. reported a series of cases with very early-onset VAP occurring within the first 48 hours of intubation. ${ }^{20}$ Most of the very early-onset group of patients had been hospitalised for some period of time prior to intubation, or reintubated because of failed weaning attempts. This explains the substantial exposure to the critical care environment prior to the intubation. Duration of mechanical ventilation is associated with multiple drugresistant pathogens. The risk factor for developing pseudomonas and MRSA is associated with duration of ventilation. It is reported that these infections constitute 40 per cent in early-onset VAP and 60 per cent of lateonset VAP. ${ }^{21}$ Longer duration of ventilation is also associated with biofilm formation causing an increase in colonising bacteria.

\section{Frequent change in ventilator circuit}

The frequent change in ventilator circuit can lead to the development of VAP. In the past, ventilator circuits were not disposable. Critically ill patients on a ventilator for an extended period of time were put on the same ventilator circuit, which led to the development of VAP. Around 30 per cent of cases in every 24-hour circuit change had a positive growth in culture compared to 32 per cent of cases in every 48-hour circuit change. Fink et al. conducted a study on extending ventilator circuit change interval beyond two days. They compared 48-hour circuit changes to 30-day circuit changes, with the longer circuit use being associated with lower VAP rates. ${ }^{22}$ The usage of a single ventilator circuit is still controversial. The maximum duration of time that a circuit can be used safely is unknown.

\section{Type of circuit}

There are different types of circuits used in ventilators. Heat and moist exchange humidifiers (HMEs) or passive devices known as artificial noses can maintain heat and humidity. Heated wire circuits have the advantage of reduced condensate development, and therefore decreased need for breakage of circuit and reduced water usage. Heat and moist exchange humidifiers have many advantages over other humidifiers: they reduce water condensation and thereby prevent bacterial colonisation; the added advantage of HMEs are that the circuit need not be broken either to remove the condensate or to aspirate the endotracheal secretions. ${ }^{23}$ The contraindications for use of HMEs are that there is risk of airway occlusion from insufficient humidity, increased dead space in patients receiving lung protective ventilation, and small tidal volumes. These humidifiers are also inexpensive. Overall, use of HME reduces the risk of VAP. 


\section{Closed versus open ventilation}

The traditional method of suctioning is the open method in which a sterile catheter is introduced and secretions are aspirated. It is associated with hyperoxygenation and the patient has to be disconnected from the ventilator. Subsequently, closed suctioning systems were introduced, which have the advantage of maintenance of oxygenation, ventilator circuit, and positive end expiratory circuit. Closed suctioning systems also reduce contamination from the caregivers and environment; however, they have to be changed daily and are very costly. In earlier studies, closed circuit catheters demonstrated higher levels of catheter colonisation, ${ }^{24}$ which occurred because the saline used for cleaning the catheter was lavaged into the airway along with the bacteria. The closed circuit reduces environmental contamination compared to the open technique. ${ }^{25}$ Closed circuits can be used safely but the maximum duration of time for which the circuits can be used safely is not known. Closed circuits have significantly reduced the cost of managing ventilated patients compared to patients treated using open suctioning systems. ${ }^{26}$

\section{Nasogastric tube}

Enteral feeding by nasogastric tube has a direct influence on gastroesophageal reflux (GER); it increases the GER among these groups of patients. Many studies have compared the site of enteral feeding and their advantages. A randomised controlled trial was conducted on the incidence of ventilatorassociated pneumonia and success in nutrient delivery with gastric versus small intestinal feeding. It was found that there was no significant difference in the development of VAP between the two study groups. ${ }^{27}$ The magnitude of the condition was unaffected by fine bore tube. A study was conducted on the rate of VAP in stroke or head injury patients receiving early gastrostomy. It was found that patients with a nasogastric tube developed VAP more frequently compared to patients who had gastrostomy. ${ }^{28}$

\section{Prone position}

The position of the ventilated patient is a risk factor for the development of VAP. In addition to VAP, the patient's position can also cause trauma to the lungs. In a mechanically ventilated patient in the supine position, the dorsal part of the lung goes into compression atelectasis and the ventral part under goes barotrauma. But when the patient is in the prone position, the dorsal part of the lung receives more air. ${ }^{29}$ This is an important reason for positioning mechanically ventilated patients prone. This has been proved by experiments conducted on rats. The advantage of lateral positioning is that it improves gas exchange, and reduces the development of gastroesophageal reflux. Lateral positioning of patients is done in such a way that the endotracheal tube end is below the level of the trachea and prevents lung infection by preventing gastric aspiration. ${ }^{30}$

\section{Tracheostomy}

Tracheostomy is typically performed in acute respiratory failure, wherein there is need for prolonged mechanical ventilation, or in those who cannot protect the airway because of facial injuries or an altered level of consciousness. The advantage of tracheostomy on reducing the incidence of VAP is controversial. In a multicentre study the rate of pneumonia was reduced among the patients on tracheostomy. ${ }^{31}$ Airway colonisation prior to the procedure appears to be a major risk factor for VAP after tracheostomy, particularly if fever is present and if continued sedation is necessary after the procedure. Tracheostomy is also an independent risk factor for VAP due to Stenotrophomonasmaltophilia.

\section{Reintubation}

Frequent reintubation is found to be a risk factor for VAP. The main cause for pneumonia associated with frequent reintubation is the aspiration of gastric contents: these patients have their nasogastric tube in place during reintubation, and their gastric contents are aspirated. ${ }^{5}$ Subglottic dysfunction and low levels of consciousness among ventilated patients is another risk associated with reintubation.

\section{Nasal intubation}

Nasal intubation followed by blockage of flow from nasal ostia is associated with nosocomial sinusitis. In a study comparing orotracheal intubation with nasotracheal intubation, there was no statistically significant difference in the incidence of VAP, though there was more sinusitis in the nasotracheal group. ${ }^{32}$

\section{Paralytic agents or sedation}

Paralytic agents or drugs associated with sedation increase the development of pneumonia. Paralytic agents are used in therapeutic procedures. In patients undergoing bronchoscopy, Midazolam is used to relax the bronchial muscles. This can result in prolonged relaxation of those muscles and lead to aspiration of the secretions. Similarly, patients on sedative drugs aspirate the secretions and develop pneumonia. Independent risk factors for very early post-intubation VAP were the use of cardiopulmonary resuscitation and continuous sedation. ${ }^{33}$

\section{$\mathrm{H}_{2}$ blockers}

VAP has significantly increased among patients who receive stress ulcer prophylaxis. A direct relationship between alkaline gastric $\mathrm{pH}$ and gastric bacterial 
colonisation has been demonstrated in several studies. ${ }^{34}$ Sucralfate appears to have a small protective effect against VAP because stress ulcer prophylactic medications that raise the gastric $\mathrm{pH}$ might themselves increase the incidence of pneumonia. This has also been proved by trials with and without the use of $\mathrm{H}_{2}$ blockers, which show an increase in VAP among those with $\mathrm{H}_{2}$ blockers.

\section{Transport out of ICU}

In a study conducted by $A^{\prime}$ Court et al., it was found that most patients had to be transported out of the ICU for conducting some procedures. It was found that 24 per cent of patients transported out of ICU developed VAP compared to 4 per cent confined to the ICU. ${ }^{35}$

\section{Microbiology of VAP}

There is an increase in aerobic gram-negative organisms among ventilated patients. Besides this, in the case of hospitalised patients, the nosocomial organisms and the organisms from the health worker and other patients can be transmitted to the patient. Microbial flora of hospitalised patients change drastically within a few days due to antibiotic administration. There is evidence that long hospital stays are associated with the emergence of resistant pathogens. ${ }^{36}$

\section{Gram-positive organisms}

Gram-positive organisms colonise the anterior nares and are important pathogens causing nosocomial infection and VAP. Methicillin-sensitive $S$. aureus (MSSA) is common among young patients, traumatic coma, and neurosurgical patients. Most gram-positive organisms are sensitive to penicillin, but there is an emergence of methicillin-resistant pathogens which are mostly community acquired. ${ }^{37}$ Risk factors for patients with MRSA include prior antibiotic treatment, COPD, longer duration of mechanical ventilation, steroid treatment, and prior bronchoscopy. Streptococcus pneumonia is another organism that can colonise the oral cavity. It is associated with development of VAP in the early days of intubation and is rapidly cleared following antibiotic therapy. ${ }^{38}$ Streptococcus pneumonia's virulence is associated with the capsular polysaccharide.

\section{Gram-negative enteric pathogens}

Gram-negative enteric pathogens are aerobic gram-negative bacilli that are normal inhabitants of the lower gastrointestinal tract. Antibiotic therapy and other infections can suppress the normal flora and increase the multiplication of these organisms. Escherichia coli and Klebsiella pneumoniae are the common pathogens isolated from ventilated patients. They are most commonly associated with extended spectrum beta lactamase (ESBL) and render the bacterium resistant to penicillin and cephalosporin antibiotics. ${ }^{39}$ The resistance to this group of drugs may be due to a variety of mechanisms other than ESBL production. It includes Amp$C$ beta-lactamase and metallo beta lactamase. In a study conducted by Joseph et al. from South India, 50 per cent of Escherichia coli and 67 per cent of Klebsiella pneumoniae were ESBL producers. Similarly, Amp-C beta lactamase was produced by 33 per cent of enterobacteriaceae. ${ }^{40}$

\section{Non-fermenters}

Pseudomonas infection is associated with risk factors like prolonged stay in the hospital, prior antibiotic therapy, and prolonged duration of mechanical ventilation. The virulence factors includes exotoxins (EXO S,T,U,Y), which are directly secreted into the cytoplasm of host cells using the type III secretion system. ${ }^{41}$ Acinetobacter species have low virulence, and the isolates are usually colonisers of the upper respiratory tract. Garnacho et al. reported that Acinetobacter VAP does not contribute to excess mortality. They showed no attributable mortality due to Acinetobacter-associated VAP, compared with a closely matched control group of patients with nonAcinetobacter VAP. ${ }^{42}$ These organisms readily spread from one patient to another by their ability to survive on inanimate objects and on healthcare workers' hands. These organisms are associated with risk factors like aspiration, ARDS, neurosurgery, and poor hand washing.

\section{Other organisms causing VAP}

Anaerobic bacteria from the oropharynx can also play an important role in VAP, as has been reported in aspiration pneumonia in nonintubated patients. A prospective surveillance study was conducted among 26 consecutive mechanically ventilated patients. Among them 15 patients became colonised by 28 different anaerobic strains. ${ }^{43}$ Around 35 per cent of the cases of Legionnaires' disease were reported to the Centers for Disease Control between 1980 and $1998 .{ }^{44}$ The rate of Legionnaires' disease varies considerably by geographic location. Sabria et al. found that most of the legionellae cases were due to water contamination. Casalta et al. identified four cases of diffuse pneumonia within several days of mechanical ventilation following vascular surgical procedures. ${ }^{45}$ Viral infections can be caused by common viruses like influenza, parainfluenza followed by herpes simplex virus and cytomegalovirus, adenovirus, respiratory syncytial virus rhinovirus, and metapneumovirus. ${ }^{33,46}$ Most reported cases of COPD patients on corticosteroid treatment are known to be at risk for invasive pulmonary aspergillosis. Candida infections are common in immunosuppressed patients. Around 24 per cent of cases 
are of non-infectious origin, and may be caused by atelectasis, chemical pneumonitis, pulmonary embolism, pulmonary contusion, pulmonary edema, and drug reaction. ${ }^{47}$

\section{Sampling}

\section{Invasive technique}

There are different methods of sample collection for VAP, including both invasive and non-invasive techniques. Bronchoalveolar lavage (BAL) is an invasive technique used in diagnosis; it requires an expert so that a proper area is selected for sampling. The fiber optic bronchoscope (FOB) has to traverse the endotracheal tube, the tracheobronchial tree, and reach the distal airways. It can lead to contamination and limits the specificity. The complications associated with bronchoscopic techniques are hypoxaemia, cardiac arrhythmias, and bronchospasm. In BAL a million alveoli are sampled from $1 \mathrm{ml}$ of secretions from the lavage fluid. ${ }^{48} \mathrm{BAL}$ samples, which collect $1 \mathrm{ml}$ of secretions in $10-100 \mathrm{~mL}$ of effluent, represents $10^{5}$ to $10^{6} \mathrm{CFU} / \mathrm{ml}$. Protected specimen brush (PSB) is another invasive technique used in the diagnosis of VAP; it consists of a double lumen catheter with PSB, which can be used to collect the lower respiratory tract sample. The major disadvantage is that it should not be used in patients with bleeding disorders; it is also associated with the complication of pneumothorax. PSB collects between 0.001 and $0.01 \mathrm{ml}$ of secretions, the presence of greater than $10^{3}$ bacteria in the originally diluted sample $(1 \mathrm{ml})$ actually represents $10^{5}$ to $10^{6} \mathrm{CFU} / \mathrm{ml}$ of pulmonary secretions. ${ }^{49}$

\section{Non-invasive technique}

Collection of samples by quantitative culture is simple, quick, and widely available. There is some evidence that this method has high false-positive rates in the diagnosis of VAP. In another study conducted by Torres et al. on non-invasive versus invasive microbial investigations in VAP, 76 patients with suspected VAP were randomly allocated to either an invasive or a non-invasive diagnostic strategy. The results showed that the invasive strategy had no benefit. ${ }^{50}$ They used a threshold of $10^{5}$ colony forming units $/ \mathrm{ml}$ as a strategy to diagnose VAP. The disadvantage of the non-invasive strategy for diagnosis of VAP is its increased tendency for higher antibiotic usage. The threshold used in quantitative cultures for the diagnosis of VAP is $10^{6} \mathrm{CFU} / \mathrm{ml}$ for tracheal aspirates. The sensitivity and specificity also vary based on the alteration of the threshold. ${ }^{51}$

\section{Gram stain}

Gram stain plays a valid role in the diagnosis of VAP. According to Blot et al., gram-stained secretion of a patient without pus cells and bacteria on treatment has a negative predictive value of 94 per cent for VAP. ${ }^{52}$ The endotracheal aspirate (ETA) may be negative for culture once obtained at the onset of VAP, but gram stain helps to identify the morphotype of the organism as either gram-positive coccus or gram-negative bacilli, thus gram stain is sensitive but not specific for samples obtained from the bronchoscopic qualitative culture technique. Timsit et al. identified a good correlation between the gram stain and culture of BAL. ${ }^{53}$ Another study showed that direct grams have reduced the inappropriate antibiotic therapy from 33 per cent to 12 per cent; ${ }^{53}$ further modified Giemsa staining is recommended as it offers better detection of intracellular bacteria, protozoa, and some fungal pathogens compared to gram staining. Around 5 per cent of BAL-obtained cells contain intracellular bacteria.

\section{Criteria for diagnosis}

Diagnosis of VAP is based on medical history and clinical examination. The clinical examination includes chest radiograph and systemic signs of infection. The chest radiograph is used to determine both lung parenchymal involvement and the presence of any pleural effusion or cavitation. The systemic signs are fever, leucocytosis, tachycardia, and some non-specific signs like release of cytokines. Fever of more than $38^{\circ} \mathrm{C}$ is an indication that a patient is developing VAP. Similarly, a leukocyte count of more than 11,000 cells/cu mm or less than $5,000 / \mathrm{cu} \mathrm{mm}$ can help in diagnosis. Torres et al. conducted a study on the validation of different techniques for diagnosis of VAP. They reported a diagnostic rule for VAP; namely, that patients with infiltration in the chest radiograph along with any two of the following-fever greater than $38.3^{\circ} \mathrm{C}$, leukocytes more than $12 \times 10^{9} / \mathrm{ml}$, and purulent tracheobronchial secretions-had VAP. It had a sensitivity of 69 per cent and specificity of 75 per cent. ${ }^{54}$ In a study by Wunderink et al., it was found that when all four signs were taken into consideration it increased the specificity but lowered the sensitivity to 50 per cent. ${ }^{55}$

In a study conducted by Pugin et al., they introduced the clinical pulmonary infection score (CPIS), a new scoring system that included the following variables: temperature, leukocyte count, volume and purulence of tracheal secretions, oxygenation, chest roentgenogram, and semi-quantitative analysis of the ETA, with gram stain. ${ }^{56}$ CPIS varies from $0-12$. Patients with CPIS more than six were considered to be affected with pneumonia. ${ }^{57}$ Papzainand et al. conducted further studies and found that CPIS more than six had a sensitivity of 7285 per cent and specificity of 85-91 per cent. ${ }^{58}$ This study had its own drawbacks like difficulty in calculating the 
semi-quantitative cultures. A CPIS of more than 6 is taken for development of pneumonia.

The triggering receptor expressed on myeloid cells (TREM-1) is used as an immunological method of diagnosis of VAP. It was found to be an accurate method for diagnosis of fungal or bacterial pneumonia with sensitivity of 98 per cent and specificity of 90 per cent. ${ }^{59}$ Procalcitonin is another marker, which is increased in the case of bacterial sepsis. The sensitivity and specificity of procalcitonin is more compared with C-reactive protein. ${ }^{60}$

\section{Treatment}

Antimicrobials are synthetic derivatives of chemical substances; antibiotics are a subset of antimicrobials derived from living microbes. Some antibiotics bind irreversibly to the binding site and are called bacteriostatic. Aminoglycosides, fluroquinolones, polymixin, colistin, and cotrimoxazole are bacteriostatic. The action of drugs in tissues is based on the maximum concentration of the drug $(\mathrm{Cmax})$ and the rate of clearance of the drug. A drug with concentration-dependent killing and prolonged post-antibiotic effect should be administered in large, infrequent doses to achieve maximum efficacy. Clinical studies have shown that adequate early antimicrobial treatment reduces the mortality rate among VAP patients compared to patients receiving inadequate therapy. ${ }^{61}$

The prevalence of antimicrobial resistance among VAP pathogens is steadily increasing. Both intrinsic resistance and acquired resistance to broadly used antimicrobial drugs are increasing. ${ }^{62}$ Staphylococcus resistance to methicillin has increased to 11 per cent and Klebsiellae resistance to thirdgeneration cephalosporins has increased to 47 per cent. ${ }^{63}$ Pseudomonas resistance to imipenem, fluroquinolones, and third-generation cephalosporins has increased to 15, 9, and 20 per cent, respectively.

MRSA are resistant to other antimicrobial drugs - the drug of choice is vancomycin. Newer drugs like Linezolid are being used; these drugs have better tissue penetration and are bacteriostatic rather than bactericidal. Wunderink et al. conducted a study comparing vancomycin with Linezolid and found that Linezolid has a therapeutic advantage compared to other drugs. ${ }^{64}$ Another established treatment for patients with MRSA is a double streptogramin combination quinupristin and dalfopristin.

Imipenem seems to be the drug of choice unless there is a very high level of carbapenems resistance. Against highly carbapenem-resistant Acinetobacter strains, rifampins are used either as monotherapy or in combination with Imipenem or tobramycin. Colistin had little effect either singly or in combination with rifampin in vitro. ${ }^{65}$ Ampicillin/sulbactam and cilastin/imipenem have equivalent efficacy for Acinetobacter spp. Intravenous colistin therapy has better results in patients with MDR Acinetobacter spp. and Pseudomonas spp. Tigecycline also has better results against carbapenem-resistant Acinetobacter spp.

\section{Optimal duration of antimicrobial therapy}

A minimum of 7-10 days treatment is recommended for hospital-acquired pneumonia and VAP caused by Haemophilus spp. and staphylococcal infections, and 1421 days treatment for typical cases that are associated with MDR non-fermenting gram-negative bacilli. ${ }^{66}$ Short course treatment for three days is recommended for lowrisk patients. Treatment can also be discontinued on the basis of clinical response. Rotating antimicrobial therapy seems to reduce the resistance of resistant strains for a particular drug. In a study it was shown that there is an improvement in patients with resistance to antimicrobial drugs by rotating antibiotics. ${ }^{67}$ The efficacy of antimicrobial drugs depends on the concentration and persistence at the site of infection. Airway delivery of drugs can reduce systemic toxicity particularly for drugs such as aminoglycosides. Aerosolised gentamicin can achieve high concentrations and it is effective, unlike aerosolised cephalosporins at preventing biofilm formation in endotracheal tube. ${ }^{68}$

De-escalation is a method of treatment that can be incorporated in patients with VAP. It refers to the use of aggressive broad-spectrum antimicrobials followed by narrowing or reducing the antimicrobial dose once the results of antimicrobial tests are available. The American Thoracic Society/Infectious Disease Society of America Guidelines advise starting on a broad-spectrum therapy for the VAP patients followed by de-escalation to a narrow-spectrum drug for the specific pathogen. ${ }^{69}$

\section{Prevention of VAP}

VAP can be prevented by following proper hand washing and using protective gloves. Host and intervention risk factors have to be monitored periodically to minimise the VAP rates. The main focus should be on reducing the aspiration of secretions and a proper antibiotic usage, thereby reducing the VAP rates. 


\section{Conclusion}

VAP is a common nosocomial infection associated with ventilated patients. The mortality associated with VAP is also high. The associated organisms and their resistance patterns vary depending on the patient group and hospital setting. Since the diagnostic method available for VAP is not universal, a proper infection control policy with appropriate antibiotic usage can reduce the mortality among ventilated patients.

\section{References}

1. Rello J, Diaz E. Pneumonia in the intensive care unit. Crit Care Med 2003;31:2544-51.

2. Alsadat $R, A l$-Bardan $H$, Mazloum $M N$, Shamah $A A$, Eltayeb MF, Marie A, Dakkak A, Naes O, Esber F, Betelmal

I, Kherallah $M$. Use of ventilator associated pneumonia bundle and statistical process control chart to decrease VAP rate in Syria. Avicenna J Med 2012;2:79-83.

3. Joseph NM, Sistla S, Dutta TK, Badhe AS, Parija SC. Ventilator-associated pneumonia in a tertiary care hospital in India: incidence and risk factors. J Infect Dev Ctries 2009;3:771-7.

4. Choudhuri AH. Ventilator-Associated Pneumonia: When to hold the breath? Int J Crit IIIn Inj Sci 2013;3:169-74.

5. Chastre J, Fagon JY. Ventilator-associated pneumonia. Am J Respir Crit Care Med 2002;165: 867-903.

6. Hunter JD. Effects of anaesthesia on the human immune system. Hosp Med 1999;60:658-63.

7. Sottile FD, Marrie TJ, Prough DS, Hobgood CD, Gower DJ, Webb LX, Costerton JW, Gristina AG. Nosocomial pulmonary infection: possible etiologic significance of bacterial adhesion to endotracheal tubes. Crit Care Med 1986;14:265-70.

8. Craven DE, Lichtenberg DA, Goularte TA, Make BJ, McCabe WR. Contaminated medication nebulizers in mechanical ventilator circuits. Source of bacterial aerosols. Am J Med 1984;77:834-8.

9. Rello J, Ausina V, Castella J, Net A, Prats G. Nosocomial respiratory tract infections in multiple trauma patients. Influence of level of consciousness with implications for therapy. Chest 1992; 102:525-9.

10. Singh N, Falestiny MN, Rogers P, Reed MJ, Pularski J, Norris R, Yu VL. Pulmonary infiltrates in the surgical ICU: prospective assessment of predictors of etiology and mortality. Chest 1998;114:1129-36.

11. Ewig S, Torres A, El-Ebiary M, Fabregas N, Hernandez C, Gonzalez J, Nicolas JM, Soto L. Bacterial colonization patterns in mechanically ventilated patients with traumatic and medical head injury. Incidence, risk factors, and association with ventilator-associated pneumonia. Am J Respir Crit Care Med 1999;159:188-98.
12. Garibaldi RA, Britt MR, Coleman ML, Reading JC, Pace NL. Risk factors for postoperative pneumonia. Am J Med 1981;70:677-80.

13. Grobmyer SR, Maniscalco SP, Purdue GF, Hunt JL. Alcohol, drug intoxication, or both at the time of burn injury as a predictor of complications and mortality in hospitalized patients with burns. J Burn Care Rehabil 1996;17:532-9.

14. Chastre J, Trouillet JL, Vuagnat A, Joly-Guillou ML, Clavier H, Dombret MC, Gibert C. Nosocomial pneumonia in patients with acute respiratory distress syndrome. Am J Respir Crit Care Med 1998;157:116572.

15. Markowicz $P$, Wolff $M$, Djedaïni $K$, Cohen $Y$, Chastre J, Delclaux C, Merrer J, Herman B, Veber B, Fontaine A, Dreyfuss D. Multicenter prospective study of ventilator-associated pneumonia during acute respiratory distress syndrome. Incidence, prognosis, and risk factors. ARDS Study Group. Am J Respir Crit Care Med 2000;161:1942-8.

16. Rello J, Torres A, Ricart M, Valles J, Gonzalez J, Artigas A, Rodriguez-Roisin R. Ventilator-associated pneumonia by Staphylococcus aureus. Comparison of methicillin-resistant and methicillin-sensitive episodes. Am J Respir Crit Care Med 1994;150:15459.

17. Bonten MJ, Gaillard CA, van der Geest S, van Tiel FH, Beysens AJ, Smeets HG, Stobberingh EE. The role of intragastric acidity and stress ulcer prophylaxis on colonization and infection in mechanically ventilated ICU patients. A stratified, randomized, double-blind study of sucralfate versus antacids. Am J Respir Crit Care Med 1995;152:1825-34.

18. Rouby JJ, Laurent P, Gosnach M, Cambau E, Lamas G, Zouaoui A, Leguillou JL, Bodin L, Khac TD, Marsault C, et al. Risk factors and clinical relevance of nosocomial maxillary sinusitis in the critically ill. Am J Respir Crit Care Med 1994;150:776-83.

19. Trouillet JL, Chastre J, Vuagnat A, Joly-Guillou ML, Combaux D, Dombret MC, Gibert C. Ventilatorassociated pneumonia caused by potentially drugresistant bacteria. Am J Respir Crit Care Med 1998;157:531-9.

20. Rello J, Diaz E, Roque M, Valles J. Risk factors for developing pneumonia within 48 hours of intubation. Am J Respir Crit Care Med 1999;159:1742-6.

21. Ibrahim EH, Ward S, Sherman G, Kollef MH. A comparative analysis of patients with early-onset vs late-onset nosocomial pneumonia in the ICU setting. Chest 2000;117:1434-42.

22. Fink JB, Krause SA, Barrett L, Schaaff D, Alex CG. Extending ventilator circuit change interval beyond 2 
days reduces the likelihood of ventilator-associated pneumonia. Chest 1998;113:405-11.

23. Prat G, Renault A, Tonnelier JM, Goetghebeur D, Oger E, Boles JM, L'Her E. Influence of the humidification device during acute respiratory distress syndrome. Intensive Care Med 2003;29:2211-5.

24. Freytag CC, Thies FL, Konig W, Welte T. Prolonged application of closed in-line suction catheters increases microbial colonization of the lower respiratory tract and bacterial growth on catheter surface. Infection 2003;31:31-7.

25. Cobley $M$, Atkins $M$, Jones PL. Environmental contamination during tracheal suction. A comparison of disposable conventional catheters with a multiple-use closed system device. Anaesthesia 1991;46:957-61.

26. Darvas JA, Hawkins LG. The closed tracheal suction catheter: 24 hour or 48 hour change? Aust Crit Care 2003;16:86-92.

27. Kearns PJ, Chin D, Mueller L, Wallace K, Jensen WA, Kirsch $\mathrm{CM}$. The incidence of ventilator-associated pneumonia and success in nutrient delivery with gastric versus small intestinal feeding: a randomized clinical trial. Crit Care Med 2000;28:1742-6.

28. Kostadima E, Kaditis AG, Alexopoulos EI, Zakynthinos E, Sfyras D. Early gastrostomy reduces the rate of ventilatorassociated pneumonia in stroke or head injury patients. Eur Respir J 2005;26:106-11.

29. Pelosi P, Brazzi L, Gattinoni L. Prone position in acute respiratory distress syndrome. Eur Respir J 2002;20: 1017-28.

30. Panigada M, Berra L, Greco G, Stylianou M, Kolobow T. Bacterial colonization of the respiratory tract following tracheal intubation-effect of gravity: an experimental study. Crit Care Med 2003;31:729-37.

31. Sugerman HJ, Wolfe L, Pasquale MD, Rogers FB, O'Malley $K F$, Knudson $M$, DiNardo $L$, Gordon $M$, Schaffer $S$. Multicenter, randomized, prospective trial of early tracheostomy. J Trauma 1997;43:741-7.

32. Holzapfel L, Chevret S, Madinier G, Ohen F, Demingeon G, Coupry A, Chaudet $M$. Influence of long-term oro- or nasotracheal intubation on nosocomial maxillary sinusitis and pneumonia: results of a prospective, randomized, clinical trial. Crit Care Med 1993;21:1132-8.

33. Park DR. The microbiology of ventilator-associated pneumonia. Respir Care 2005;50:742-63.

34. Atherton ST, White DJ. Stomach as source of bacteria colonising respiratory tract during artificial ventilation. Lancet 1978;2:968-9.

35. A'Court CH, Garrard CS, Crook D, Bowler I, Conlon C, Peto $T$, Anderson E. Microbiological lung surveillance in mechanically ventilated patients, using non-directed bronchial lavage and quantitative culture. Q J Med 1993;86:635-48.

36. Tillotson JR, Finland M. Bacterial colonization and clinical superinfection of the respiratory tract complicating antibiotic treatment of pneumonia. J Infect Dis 1969;119:597-624.

37. Stevens DL. Community-acquired Staphylococcus aureus infections: Increasing virulence and emerging methicillin resistance in the new millennium. Curr Opin Infect Dis 2003;16:189-91.

38. Dennesen PJ, van d, V, Kessels AG, Ramsay G, Bonten MJ. Resolution of infectious parameters after antimicrobial therapy in patients with ventilatorassociated pneumonia. Am J Respir Crit Care Med 2001;163:1371-5.

39. Colodner R. Extended-spectrum beta-lactamases: a challenge for clinical microbiologists and infection control specialists. Am J Infect Control 2005;33:1047.

40. Joseph NM, Sistla S, Dutta TK, Badhe AS, Rasitha D, Parija SC. Ventilator-associated pneumonia in a tertiary care hospital in India: role of multi-drug resistant pathogens. J Infect Dev Ctries 2010;4:21825.

41. Galan JE, Collmer A. Type III secretion machines: bacterial devices for protein delivery into host cells. Science 1999;284:1322-8.

42. Garnacho J, Sole-Violan J, Sa-Borges M, Diaz E, Rello J. Clinical impact of pneumonia caused by Acinetobacter baumannii in intubated patients: a matched cohort study. Crit Care Med 2003;31:247882.

43. Robert R, Grollier G, Frat JP, Godet C, Adoun M, Fauchère $\mathrm{JL}$, Doré $P$. Colonization of lower respiratory tract with anaerobic bacteria in mechanically ventilated patients. Intensive Care Med 2003;29:1062-8.

44. Benin $\mathrm{AL}$, Benson RF, Besser RE. Trends in legionnaires disease, 1980-1998: declining mortality and new patterns of diagnosis. Clin Infect Dis 2002;35:1039-46.

45. Casalta JP, Piquet P, Alazia M, Guidon-Attali C, Drancourt M, Raoult D. Mycoplasma pneumoniae pneumonia following assisted ventilation. Am J Med 1996;101:165-9.

46. Vaideeswar P, Bavdekar SB, Biswas P, Sarangarajan R, Bhosale A. Viral ventilator-associated pneumonia: uncovering tip of the iceberg. Indian J Pathol Microbiol 2011;54:339-43.

47. Koenig SM, Truwit JD. Ventilator-associated pneumonia: diagnosis, treatment, and prevention. Clin Microbiol Rev 2006;19:637-57. 
48. Rennard SI, Aalbers R, Bleecker E, Klech H, Rosenwasser L, Olivieri D, Sibille Y. Bronchoalveolar lavage: performance, sampling procedure, processing and assessment. Eur Respir J Suppl 1998;26:13S-5S.

49. Baselski V. Microbiologic diagnosis of ventilatorassociated pneumonia. Infect Dis Clin North Am 1993;7:331-57.

50. Ruiz M, Torres A, Ewig S, Marcos MA, Alcón A, Lledó R, Asenjo MA, Maldonaldo A. Noninvasive versus invasive microbial investigation in ventilator-associated pneumonia: evaluation of outcome. Am J Respir Crit Care Med 2000;162:119-25.

51. Fàbregas N, Ewig S, Torres A, El-Ebiary M, Ramirez J, de La Bellacasa JP, Bauer T, Cabello $\mathrm{H}$. Clinical diagnosis of ventilator associated pneumonia revisited: comparative validation using immediate post-mortem lung biopsies. Thorax 1999;54:867-73.

52. Blot F, Raynard B, Chachaty E, Tancrede C, Antoun S, Nitenberg G. Value of gram stain examination of lower respiratory tract secretions for early diagnosis of nosocomial pneumonia. Am J Respir Crit Care Med 2000;162:1731-7.

53. Timsit JF, Cheval C, Gachot B, Bruneel F, Wolff M, Carlet J, Regnier B. Usefulness of a strategy based on bronchoscopy with direct examination of bronchoalveolar lavage fluid in the initial antibiotic therapy of suspected ventilator-associated pneumonia. Intensive Care Med 2001;27:640-7.

54. Torres A, el-Ebiary M, Padró L, Gonzalez J, de la Bellacasa JP, Ramirez J, Xaubet A, Ferrer M, Rodriguez-Roisin R. Validation of different techniques for the diagnosis of ventilator-associated pneumonia. Comparison with immediate postmortem pulmonary biopsy. Am J Respir Crit Care Med 1994;149:324-31.

55. Wunderink RG. Clinical criteria in the diagnosis of ventilator-associated pneumonia. Chest 2000;117:191S4S.

56. Pugin J, Auckenthaler R, Mili N, Janssens JP, Lew PD, Suter PM. Diagnosis of ventilator-associated pneumonia by bacteriologic analysis of bronchoscopic and nonbronchoscopic "blind" bronchoalveolar lavage fluid. Am Rev Respir Dis 1991;143:1121-9.

57. Pugin J. Clinical signs and scores for the diagnosis of ventilator-associated pneumonia. Minerva Anestesiol 2002;68:261-5.

58. Papazian L, Thomas P, Garbe L, Guignon I, Thirion X, Charrel J, Bollet C, Fuentes P, Gouin F. Bronchoscopic or blind sampling techniques for the diagnosis of ventilatorassociated pneumonia. Am J Respir Crit Care Med 1995;152:1982-91.

59. Gibot S, Cravoisy A, Levy B, Bene MC, Faure G, Bollaert PE. Soluble triggering receptor expressed on myeloid cells and the diagnosis of pneumonia. N Engl J Med 2004;350:451-8.

60. Harbarth S, Holeckova K, Froidevaux C, Pittet D, Ricou B, Grau GE, Vadas L, Pugin J; Geneva Sepsis Network. Diagnostic value of procalcitonin, interleukin-6, and interleukin-8 in critically ill patients admitted with suspected sepsis. Am J Respir Crit Care Med 2001;164:396-402.

61. Iregui M, Ward S, Sherman G, Fraser VJ, Kollef MH. Clinical importance of delays in the initiation of appropriate antibiotic treatment for ventilatorassociated pneumonia. Chest 2002;122:262-8.

62. Park DR. Antimicrobial treatment of ventilatorassociated pneumonia. Respir Care 2005;50:932-52.

63. National Nosocomial Infections Surveillance (NNIS) System Report, data summary from January 1992 through June 2004, issued October 2004. Am J Infect Control 2004;32:470-85.

64. Wunderink RG, Rello J, Cammarata SK, Croos-Dabrera $\mathrm{RV}$, Kollef $\mathrm{MH}$. Linezolid vs vancomycin: analysis of two double-blind studies of patients with methicillinresistant Staphylococcus aureus nosocomial pneumonia. Chest 2003;124:1789-97.

65. Montero A, Ariza J, Corbella X, Doménech A, Cabellos C, Ayats J, Tubau F, Borraz C, Gudiol F. Antibiotic combinations for serious infections caused by carbapenem-resistant Acinetobacter baumannii in a mouse pneumonia model. J Antimicrob Chemother 2004;54:1085-91.

66. American Thoracic Society. Hospital-acquired pneumonia in adults: diagnosis, assessment of severity, initial antimicrobial therapy, and preventive strategies. A consensus statement, American Thoracic Society, November 1995. Am J Respir Crit Care Med 1996;153:1711-25.

67. Gruson D, Hilbert G, Vargas F, Valentino R, Bui N, Pereyre S, Bebear C, Bebear CM, Gbikpi-Benissan G. Strategy of antibiotic rotation: long-term effect on incidence and susceptibilities of Gram-negative bacilli responsible for ventilator-associated pneumonia. Crit Care Med 2003;31:1908-14.

68. Adair CG, Gorman SP, Byers LM, Jones DS, Feron B, Crowe M, Webb HC, McCarthy GJ, Milligan KR. Eradication of endotracheal tube biofilm by nebulised gentamicin. Intensive Care Med 2002;28:426-31.

69. American Thoracic Society. Guidelines for the management of adults with hospital-acquired, ventilator-associated, and healthcare-associated pneumonia. Am J Respir Crit Care Med 2005;171:388-416. 


\section{PEER REVIEW}

Not commissioned.

\section{CONFLICTS OF INTEREST}

The authors declare that they have no competing interests. 